\title{
Electrotherapeutic Interventions for Tennis Elbow or Lateral Epicondylitis: A Brief Review of the Literature
}

\author{
${ }^{1}$ Levent Ediz and ${ }^{2}$ Mahmut Alpayci \\ ${ }^{1}$ Department of Physical Medicine and Rehabilitation, Medical Faculty, Yuzuncu Yil University, Van, Turkey \\ ${ }^{2}$ Department of Physical Medicine and Rehabilitation, Bitlis State Hospital, Bitlis, Turkey
}

\begin{abstract}
Lateral Epicondylitis (LE) or tennis elbow is a painful and functionally limiting entity affecting the upper limb and hand. The lack of sufficient understanding regarding its pathophysiology has led to a large number of treatment approaches in physiotherapy practice including electrotherapeutic interventions. In the current review we evaluated recent trials and reviews of electrotherapeutic interventions for LE treatment for evidence supporting their use. For this purpose, a review of the literature on the effectiveness of low level laser therapy, ultrasound, phonophoresis, shortwave diathermy, electromagnetic field therapy, iontophoresis and extracorporeal shock wave therapy for LE was carried out. In conclusion, the literature to date has assessed the effect of a range of electrotherapeutic interventions on various outcomes for LE. At present, use of selected electrotherapeutic intervention with stretching/strengthening exercises are indicated. At this time, in the light of literature, none of the currently used electrotherapeutic intervention can be refuted in the treatment of LE.
\end{abstract}

Keywords: Lateral Epicondylitis, Tennis Elbow, Electrotherapy, Rehabilitation

\section{INTRODUCTION}

Lateral Epicondylitis (LE) or tennis elbow is a tendinopathy of the common extensor-supinator tendon of the elbow. The disorder is characterized by pain and tenderness over the lateral epicondyle of the humerus exacerbated by gripping (Andrews, 1996). LE was first described Major (1983) as a condition causing lateral elbow pain in tennis players.

The aetiology has been supposed to be over-use damage to the forearm extensor muscles. Inflammation present in the very early stages of the disease. There is little evidence of inflammation in chronic stages (Alfredson and Lorentzon, 2002). The dominant arm is more often affected than the non-dominant arm. Development of tennis elbow is usually insidious, although the onset may result from strenuous overuse relating to particular repetitive actions. The duration of LE is highly variable, ranging from 3 weeks to several years. The disorder is generally self-limiting and symptoms seem to resolve between 8 and 24 months in most patients (Smidt et al., 2006).

Despite the commonly used term 'tennis elbow', more than $95 \%$ of sufferers do not play regular predisposing sport, although up to $50 \%$ of tennis players are said to be affected at some time in their playing life (Wadsworth, 1987; Binder and Hazelman, 1983). The highest incidence is found in persons $30-60$ years old. With an incidence of approximately $4-7 \%$ per 1000 patients per year in general practice and a prevalence of $2-3 \%$ of adults per year, tennis elbow is one of the most often diagnosed pathology of the upper extremity. LE occurs much more frequently than medial epicondylitis, with ratios ranging from $4: 1$ to $7: 1$. While males are more often affected than females in tennis players, the incidence is equal among men and women in the general population (Smidt et al., 2006; Verhaar, 1994; Ashe et al., 2004; Walker-Bone et al., 2004).

The pathophysiology of LE is poorly understood. Although a few studies have demonstrated the presence

Corresponding Author: Levent Ediz, Department of Physical Medicine and Rehabilitation, Medical Faculty, Yuzuncu Yil University, Van, Turkey 
of the neuropeptides, calcitonin related gene peptide and substance $\mathrm{P}$ in sensory nevre fibres supplying the extensor carpi radialis brevis (Ljung et al., 1999; Fedorczyk, 2006), the others show that histologically, an angiofibroblastic proliferation is more characteristic of a failed healing response rather than of an inflammatory process. Anatomically, repetetive injury to the extensor carpi radialis brevis origin appears to be multifaceted, involving hypovascular zones, eccentric tendon stresses (Saccomanni, 2010; Erak et al., 2004; Kraushaar and Nirschl, 1999; Scott et al., 2004).

This lack of understanding regarding its pathophysiology has led to a large number of treatment modalities, including rest, modification of activity, splints, analgesic and anti-inflammatory drugs, different types of injection (corticosteroid and noncorticosteroid injections such as platelet-rich plasma, botulinum toxin, autologous blood, proteinases), physiotherapy including electrotherapeutic interventions and surgery have all been investigated and have found to end up with variable clinical benefit (Assendfelt et al., 1996; Trudel et al., 2004; Schleicher et al., 2010). Up to $30 \%$ of LE patients seen in primary care are referred to physical therapy. And the electrotherapeutic interventions are mostly included in physical therapy regimens (Jones, 2009; Bisset et al., 2005; Chung et al., 2005). The aim of this review is to evaluate the evidence of effectiveness of electrotherapeutic interventions in the management of LE.

\section{MATERIALS AND METHODS}

\subsection{Literature Search}

A literature search was performed on Medline, Embase, Cinahl, PedRo and the Cochrane Controlled Trial Register. Randomized controlled trials and previous reviews were reviewed using the key words tennis elbow, lateral epicondylitis, lateral epicondylopathy, lateral elbow pain, elbow tendonitis, lateral epicondylalgia, extensor carpi radialis tendonitis, physical therapy, rehabilitation, physiotherapy, modality, modalities, electrotherapy, electrptherapeutic intervention, ultrasound, ultrasound therapy, short wave diathermy, pulsed shortwave diathermy, electromagnetic therapy, electromagnetic field therapy, laser therapy, low level laser therapy, Extracorporeal Shock Wave Therapy (ESWT) either individually or in various combinations.

\section{RESULTS AND DISCUSSION}

\subsection{Low Level Laser Therapy (LLLT)}

The available material suggests that LLLT is safe and effective in the treatment of LE and that LLLT acts in a dose-dependent manner by biological mechanisms including biostimulatory effect on collagen production which modulate both tendon inflammation and tendon repair processes (Emanet et al., 2010; Bjordal et al., 2008). These effects of LLLT is dose-dependent (Bjordal et al., 2001) and could be induced by between 630 and $1064 \mathrm{~nm}$ wavelengths. Pain relief, painfree grip strength and global improvement showed significantly better results after LLLT than placebo. Especially with $904 \mathrm{~nm}$ wavelength therapy is appearing as a safe and effective alternative to NSAIDs and corticosteroid injections in long term follow-up (Stergioulas, 2007; Lam and Cheing, 2007; Vasseljen et al., 1992; Haker and Lundeberg, 1991).

\subsection{Ultrasound Therapy and Phonophoresis}

Ultrasound therapy (US) has been shown to be beneficial in accelerating fracture healing and has produced positive results in tendon repair (Takakura et al., 2002; Cook, 2001; Heckman et al., 1994). There is also evidence to support the use of ultrasound therapy in the treatment of lateral epicondylitis (Binder and Hazelman, 1983; Halle et al., 1986; Davidson et al., 2001). But the evidence of the effectiveness of US therapy in LE treatment seems to be less prominent than that of LLLT.

Some trials showed that using ultrasound alone and ultrasound in combination with other treatment modalities could decrease symptoms from lateral epicondylitis. The studies by Stratford et al. (1989); Binder et al. (1985); Oken et al. (2008) and Lundeberg et al. (1988) found significant short-term effects in reducing pain using ultrasound alone.

In contrast to these studies, D'Vaz et al. (2006) found US was no more effective for a large treatment effect than placebo for recalcitrant LE. A few studies also found that progressive exercise therapy is more beneficial than ultrasound in acute and chronic lateral epicondylitis (Pienimaki et al., 1996; 1998). Two reviews by Trudel et al. (2004) and Smidt et al. (2003) found that the studies that compared ultrasound with a placebo ultrasound show statistically significant and clinically relevant differences in favor of ultrasound.

One study evaluated the efficacy of phonophoresisthat is, US with a hydrocortisone coupling gel. In that sudy, outcome measures after nine treatment sessions 
did not support the use of hydrocortisone coupling gel, finding no added benefits over that of US alone (Stratford et al., 1989). Cabak et al. (2005) found significant differences between phonophoresis and ultrasound therapy. Their results support the application of phonophoresis with ketoprofen in the treatment of epicondylitis.

\subsection{Shortwave Diathermy or Pulsed Electromagnetic Field Therapy and Ionisation}

Electromagnetic Field Therapy (EMFT) or Shortwave Diathermy (SWD) has numerous biologic effects on tissues. EMFT may increase vascular circulation and change tissue temperature, which directly results in an increase in pain threshold and a decrease in swelling and pain (Kitchen and Partridge, 1992). The effects of EMFT in increasing tissue temperature and circulation and reducing pain in patients with degenerative musculoskeletal conditions have been well documented (Jan et al, 1993; Svarcova et al., 1987; Kloth and Ziskin, 1996; Ibiwoye et al., 2004; Trock, 2000).

But there is little evidence to support the use of EMFT in the treatment of LE. Unfortunately up to date only two studies investigated its effectiveness Vs a placebo. So there is need to more trials investigating the effect of EMFT in the treatment of LE. One of these two studies found no differences between groups at final outcome, following 8 weeks of therapy (Devereaux et al., 1985). And the other found significant differences between groups in favour of EMFT group at final outcome (Uzunca et al., 2007).

Within the ionisation trials, the study by Nirschl et al. (2003) showed no significantly difference in global improvement score between intervention group (corticosteroid solution) and placebo group. The study by Vecchini and Grossi (1984) found that ionization with diclofenac resulted in a significantly greater reduction in pain and global improvement scores compared with placebo ionization with saline. The study by Demirtas and Oner (1998) found that ionization with diclofenac for ten days followed by infrared treatment had a significantly greater reduction in pain scores compared with ionization with sodium salicylate and infrared treatment.

Grossi et al. (1986) compared ionisation with two dose levels of a NSAID with sham ionisation and found pain scores were significantly lower in both the high and low dose NSAID groups than in the sham group. There were no significant differences between the saline ionisation and sham groups in their study. Runeson and
Haker (2002) also compared iontophoresis with corticosteroid solution to iontophoresis with saline and found global improvement outcome at one to three months was not significant. Their results did not support the use of corticosteroid solution in iontophoresis. In summary, although this contradiction in results and the heterogeneity of interventions in the trials, there is some evidence in the majority of studies to support the use of ionisation modality in the treatment of LE.

\subsection{Extracorporeal Shock Wave Therapy (ESWT)}

ESWT has been used since the early 1990s for the treatment of tendinopathies. Randomized control trials on the effectiveness of ESWT on LE have been also done since 1996. Most of these studies were performed on individuals affected by LE who had had symptoms for greater than 12 months and who had previous failed therapy (Haake et al., 2002; Melikyan et al., 2003; Rompe et al., 1996; Speed et al., 2002). Both Haake et al. (2002) and Melikyan et al. (2003) showed no differences between ESWT and placebo groups for any of the measured end points. Moreover, Haake et al. (2002) reported significantly more side effects (transitory reddening of the skin, pain and small haematomas) in the ESWT group. Speed et al. (2002) documented no significant changes in pain scores in ESWT group.

Not consistent with these studies, Rompe et al. (1996) reported very high success rates for ESWT group in subjects with durations of symptoms of greater than 12 months, Crowther et al. (2002) also demonstrated a significant treatment effect for ESWT in patients with LE, although this effect was not found to be greater than that of corticosteroid injection.

From the results of study by Helbig et al. (2001), ESWT may be beneficial for acutely affected individuals, especially for such individuals who require pain relief within 2-4 months. However, the results of study by Chung et al. (2005) do not support the use of ESWT for LE in individuals who have previously been untreated for LE.

We found little evidence in this review of the literature to support the use of ESWT for the treatment of LE and is in keeping with recent systematic reviews of ESWT for LE that have drawn similar conclusions (Bisset et al., 2005).

\section{CONCLUSION}

Although there is evidence supporting the use of several different electrotherapeutic interventions for the 
treatment of LE, there is a strong need for larger, higher quality randomized controlled trials in this area. Although most studies are able to demonstrate short-term benefits of selected electrotherapeutic intervention, there is a lack of high-quality data demonstrating that these electrotherapeutic treatments have long-term benefits, particularly, with regard to functional outcomes.

\section{REFERENCES}

Alfredson, H. and R. Lorentzon, 2002. Chronic tendon pain: No signs of chemical inflammation but high concentrations of the neurotransmitter glutamate. Implications for treatment? Curr. Drug. Targets, 3: 43-54. DOI: 10.2174/1389450023348028

Andrews, J.R., 1996. Elbow Rehabilitation. In: Handbook of Orthopaedic Rehabilitation, Brotzman, S.B. (Ed.), Mosby, St. Louis, ISBN-10: 0815111029, pp: 67-91.

Ashe, M.C., T. McCauley and K.M. Khan, 2004. Tendinopathies of the upper extremity. A paradigm shift. J Hand Ther., 17: 329-334. DOI: 10.1197/j.jht.2004.04.002

Assendfelt, W.J., E.M. Hay, R. Adshead and L.M. Bouter, 1996. Corticosteroid injections for lateral epicondylitis: A systematic overview. Br. J. Gen. Pract., 46: 209-216. PMID: 8703521

Binder, A., G. Hodge, A.M. Greenwood, B.L. Hazleman and D.P. Page Thomas, 1985. Is therapeutic ultrasound effective in treating soft tissue lesions? BMJ. 290: 512-514. DOI: 10.1136/bmj. 290.6467 .512

Binder, A.I. and B.L. Hazelman, 1983. Lateral humeral epicondylitis-a study of natural history and the effect of conservative therapy. Br. J. Rheumatol., 22: 7376. DOI: $10.1093 /$ rheumatology/22.2.73

Bisset, L., A. Paungmali, B. Vicenzino and E. Beller, 2005. A systematic review and meta-analysis of clinical trials on physical interventions for lateral epicondylalgia. Br. J. Sports Med., 39: 411-422. DOI: $10.1136 /$ bjsm.2004.016170

Bjordal, J. Magnus, Couppe, Christian and Ljunggren et al., 2001. Low level laser therapy for tendinopathy. Evidence of a dose-response pattern. Phys. Therapy Rev., 6: 91-99. DOI: 10.1179/108331901786166569

Bjordal, J.M., R.A.B. Lopes-Martins, J. Joensen, C. Couppe and A.E. Ljunggren et al., 2008. A systematic review with procedural assessments and meta-analysis of low level laser therapy in lateral elbow tendinopathy (tennis elbow). BMC Musculoskelet Disord., 29: 75-75. DOI: 10.1186/1471-2474-9-75
Cabak, A., M. Maczewska, M. Lyp, J. Dobosz and U. Gasiorowska, 2005. The effectiveness of phonophoresis with ketoprofen in the treatment of epicondylopathy. Ortop. Traumatol. Rehabil.., 30: 660-665. PMID: 17611432

Chung, B., J.P. Wiley and M.S. Rose, 2005. Long-term effectiveness of extracorporeal shockwave therapy in the treatment of previously untreated lateral epicondylitis. Clin. J. Sport Med., 15: 305-312. DOI: 10.1097/01.jsm.0000179137.69598.7e

Cook, S., 2001. Experimental models of cartilage repair: Improved cartilage repair after treatment with lowintensity pulsed ultrasound. Clin. Orth. Rel. Res., 391: 231-243. DOI: 10.1097/00003086-20011000100022

Crowther, M.A.A., S. Registrar and G.C. Bannister, 2002. A prospective, randomised study to compare extracorporeal shock-wave therapy and injection of steroid for the treatment of tennis elbow. J. Bone Joint Surg. Br., 84: 678-679. DOI: 10.1302/0301620X.84B5.12741

D’Vaz, A.P., A.J.K. Ostor, C.A. Speed, J.R. Jenner and M. Bradley et al., 2006. Pulsed low-intensity ultrasound therapy for chronic lateral epicondylitis: A randomized controlled trial. Rheumatology, 45: 566-570. DOI: 10.1093/rheumatology/kei210

Davidson, J.H., A. Vandervoort, L. Lessard and L. Miller, 2001. The effect of acupuncture versus ultrasound on pain level, grip strength and disability in individuals with lateral epicondylitis: A pilot study. Physiother. Can., 53: 195-202.

Demirtas, R.N. and C. Oner, 1998. The treatment of lateral epicondylitis by iontophoresis of sodium salicylate and sodium diclofenac. Clin. Rehabil., 12: 23-29. DOI: 10.1191/026921598672378032

Devereaux, M., B.L. Hazleman and P.P. Thomas, 1985. Chronic humeral epicondylitis: A double-blind controlled assessment of pulsed electromagnetic field therapy. Clin. Exp. Rheumatol., 3: 333-336. PMID: 4085165

Emanet, S.K., L.I. Altan and M. Yurtkuran, 2010. Investigation of the effect of GaAs laser therapy on lateral epicondylitis. Photomed. Laser Surg., 28: 397-403. DOI: 10.1089/pho.2009.2555

Erak, S., R. Day and A. Wang, 2004. The role of supinator in the pathogenesis of chronic lateral elbow pain: A biomechanical study. J. Hand Surg. Br., 29: 461-464. DOI: 10.1016/j.jhsb.2004.06.001

Fedorczyk, J.M., 2006. Tennis elbow: Blending basic science with clinical practice. J. Hand Ther., 19: 146-153. DOI: 10.1197/j.jht.2006.02.016 
Grossi, E., G.C. Monza, S. Pollavini and L. Bona, 1986. NSAID ionisation in the management of soft-tissue rheumatism: Role played by the drug, electrical stimulation and suggestion. Clin. Exp. Rheumatol., 4: 265-267. PMID: 3533340

Haake, M., I.R. Konig, T. Decker, C. Riedel and M. Buch et al., 2002. Extracorporeal shock wave therapy in the treatment of lateral epicondylitis: A randomized multicenter trial. J. Bone Joint Surg. Am., 84: 1982-1991. PMID: 12429759

Haker, E. and T. Lundeberg, 1991. Is low-energy laser treatment effective in lateral epicondylalgia? J. Pain Symptom Manage., 6: 241-246. DOI: 10.1016/08853924(91)90014-U

Halle, J.S., R.J. Franklin and B.L. Karalfa, 1986. Comparison of four treatment approaches for lateral epicondylitis of the elbow. J. Orthop. Sports Ther., 8: 62-69. PMID: 18802239

Heckman, J.D., J.P. Ryaby, J. McCabe, J.J. Frey and R.F. Kilcoyne, 1994. Acceleration of tibial fracturehealing by non-invasive, low-intensity pulsed ultrasound. J. Bone Joint Surg., 76: 26-34. PMID: 288661

Helbig, K., 2001. Correlations between the duration of pain and the success of shock wave therapy. Clin. Orthop., 387: 68-71. DOI: 10.1097/00003086200106000-00009

Ibiwoye, M.O., K.A. Powell, M.D. Grabiner, T.E. Patterson and Y. Sakai et al., 2004. Bone mass is preserved in a critical-sized osteotomy by low energy pulsed electromagnetic fields as quantitated by in vivo micro-computed tomography. Orthop. Res., 22: 1086-1093. DOI: 10.1016/j.orthres.2003.12.017

Jan, M.H., P.K. Yip; and K.H. Lin, 1993. Change of arterial blood flow and skin temperature after direct and indirect shortwave heating on knee. Formosan J. Physical Therapy, 18: 64-71.

Jones, V., 2009. Physiotherapy in the management of tennis elbow: A review. Shoulder Elbow, 1: 108113. DOI: $10.1111 /$ j.1758-5740.2009.00023.x

Kitchen, S. and C. Partridge, 1992. Review of shortwave diathermy continuous and pulsed patterns. Physiotherapy, 78: 243-252. DOI: 10.1016/S00319406(10)61434-4

Kloth, L.C. and M.C. Ziskin, 1996. Diathermy and Pulsed Electromagnetic Fields. In: Thermal Agents in Rehabilitation, Michlovitz, S.L. (Ed.), FA Davis Co., Philadelphia, Pa., ISBN-10: 0803600445, pp: 170-199.
Kraushaar, B.S. and R.P. Nirschl, 1999. Tendinosis of the elbow (tennis elbow). Clinical features and findings of histological, immunohistochemical and electron microscopy studies. J Bone Joint Surg. Am., 81: 259-278. PMID: 10073590

Lam, L.K. and G.L. Cheing, 2007. Effects of 904-nm low-level laser therapy in the management of lateral epicondylitis: A randomized controlled trial. Photomed Laser Surg., 25: 65-71. DOI: 10.1089/pho.2006.2047

Ljung, B.O., S. Forsgren and J. Friden, 1999. Substance $\mathrm{P}$ and calcitonin gene-related peptide expression at the extensor carpi radialis brevis muscle origin: Implications for the etiology of tennis elbow. J. Orthop. Res., 17: 554-559. DOI: 10.1002/jor.1100170414

Lundeberg, T., P. Abrahamsson and E. Haker, 1988. A comparative study of continuous ultrasound, placebo ultrasound and rest in epicondylalgia. Scand J. Rehab. Med., 20: 99-101. PMID: 3187466

Major, H.P., 1983. Lawn-tennis elbow. Br. Med. J., 2: 557-557.

Melikyan, E.Y., E. Shahin, J. Miles and L.C. Bainbridge et al., 2003. Extracorporeal shock-wave treatment for tennis elbow: A randomised double-blind study. J. Bone Joint Surg. Br., 85: 852-855. PMID: 12931804

Nirschl, R.P., D.M. Rodin, D.H. Ochiai and C. Maartmann-Moe, 2003. Iontophoretic administration of dexamethasone sodium phosphate for acute epicondylitis: A randomized, double-blinded, placebo-controlled study. Am. J. Sports Med., 31: 189-195. PMID: 12642251

Oken, O., Y. Kahraman, F. Ayhan, S. Canpolat and Z.R. Yorgancioglu, 2008. The short-term efficacy of laser, brace and ultrasound treatment in lateral epicondylitis: A prospective, randomized, controlled trial. J. Hand Ther., 21: 63-67. DOI: 10.1197/j.jht.2007.09.003

Pienimaki, T., P. Karinen, T. Kemila, P. Koivukangas and H. Vanharanta, 1998. Long-term follow-up of conservatively treated chronic tennis elbow patients. A prospective and retrospective analysis. Scand J. Rehab. Med., 30: 159-66.

Pienimaki, T., T.K. Tarvainen, P.T. Siira and H. Vanharantaet, 1996. Progressive strengthening and stretching exercises and ultrasound for chronic lateral epicondylitis. Physiotherapy, 82: 522-530. DOI: 10.1016/S0031-9406(05)66275-X 
Rompe, J.D., C. Hopf, K. Kullmer, J. Heine and R. Burger et al., 1996. Low-energy extracorporal shock wave therapy for persistent tennis elbow. Int. Orthop., 20: 23-27. DOI: 10.1007/s002640050021

Runeson, L. and E. Haker, 2002. Iontophoresis with cortisone in the treatment of lateral epicondylalgia (tennis elbow): A double-blind study. Scand J. Med. Sci. Sports, 12: 136-142. DOI: 10.1034/j.16000838.2002.02142.x

Saccomanni, B., 2010. Corticosteroid injection for tennis elbow or lateral epicondylitis: A review of the literature. Curr. Rev. Musculoskelet Med., 3: 38-40. DOI: $10.1007 / \mathrm{s} 12178-010-9066-3$

Schleicher, I., G. Szalay and J. Kordelle, 2010. Treatment of epicondylitis-a current review. Sportverletz Sportschaden, 24: 218-224. DOI: 10.1055/s-0029-1245441

Scott, A., K.M. Khan, C.R. Roberts, J.L. Cook and V. Duronio, 2004. What do we mean by the term 'inflammation? A contemporary basic science update for sports medicine. Br. J. Sports Med., 38: 372-380. DOI: 10.1136/bjsm.2004.011312

Smidt, N., M. Lewis, D.A. Windt, E.M. Hay and L.M. Bouter et al., 2006. Lateral epicondylitis in general practice: Course and prognostic indicators of outcome. J. Rheumatol., 33: 2053-2059. PMID: 16881095

Smidt, N., W. Assendelft, H. Arola, A. Malmivaara and S. Green et al., 2003. Effectiveness of physiotherapy for lateral epicondylitis: A systematic review. Ann. Med., 35: 51-62. DOI: 10.1080/07853890310004138

Speed, C.A., D. Nichols, C. Richards, H. Humphreys and J.T. Wies et al., 2002. Extracorporeal shock wave therapy for lateral epicondylitis-a double blind randomised controlled trial. J. Orthop Res., 20: 895898. DOI: 10.1016/S0736-0266(02)00013-X

Stergioulas, A., 2007. Effects of low-level laser and plyometric exercises in the treatment of lateral epicondylitis. Photomed. Laser Surg., 25: 205-213. DOI: 10.1089/pho.2007.2041

Stratford, P.W., D.R. Levy, S. Gualdie, D. Miseferi and K Levy, 1989. The evaluation of phonophoresis and friction massage as treatments for extensor carpi radialis tendinitis: A randomized controlled trial. Physiother Can., 41: 93-99.
Svarcova, J., K. Trnavsky and J. Zvarova, 1987. The influence of ultrasound, galvanic currents and shortwave diathermy on pain intensity in patients with osteoarthritis. Scand. J. Rheumatol., 67: 83-85. DOI: 10.3109/03009748809105306

Takakura, Y., N. Matsui, S. Yoshiya, H. Fujioka and H. Muratsu et al., 2002. Low-intensity pulsed ultrasound enhances early healing of medial collateral ligament injuries in rats. J. Ultrasound Med., 21: 283-288. PMID: 11883539

Trock, D.H., 2000. Electromagnetic fields and magnets. Investigational treatment for musculoskeletal disorders. Rheum Dis. Clin. North Am., 26: 51-62. DOI: $10.1016 / \mathrm{S} 0889-857 \mathrm{X}(05) 70119-8$

Trudel, D., J. Duley, I. Zastrow, E.W. Kerr and R. Davidson et al., 2004. Rehabilitation for patients with lateral epicondylitis: A systematic review. J. Hand Ther., 17: 243-266. PMID: 15162109

Uzunca, K., M. Birtane and N. Taştekin, 2007. Effectiveness of pulsed electromagnetic field therapy in lateral epicondylitis. Clin. Rheumatol., 26: 69-74. DOI: 10.1007/s10067-006-0247-9

Vasseljen, Jr. O., N. Hoeg, B. Kjeldstad, A. Johnsson and S. Larsen, 1992. Low level laser versus placebo in the treatment of tennis elbow. Scand. J. Rehabil. Med., 24: 37-42. PMID: 1604260

Vecchini, L. and E. Grossi, 1984. Ionization with diclofenac sodium in rheumatic disorders: A doubleblind placebo-controlled trial. J. Int. Med. Res., 12: 346-350. PMID: 6394405

Verhaar, J.A., 1994. Tennis elbow. Anatomical, epidemiological and therapeutic aspects. Int. Orthop., 18: 263-267. PMID: 7852001

Wadsworth, T.G., 1987. Tennis elbow: Conservative, surgical and manipulative treatment. Br. Med. J., 294: 621-23. DOI: 10.1136/bmj.294.6572.621

Walker-Bone, K., K.T. Palmer, I. Reading, D. Coggon and C. Cooper, 2004. Prevalence and impact of musculoskeletal disorders of the upper limb in the general population. Arthritis Rheum., 51: 642-651. DOI: $10.1002 /$ art.20535 